\title{
Idiopathic and neurogenic detrusor overactivity: do the different patterns have urodynamic characteristics related to gender or neurological condition?
}

\author{
Françoise A. Valentini, Brigitte G. Marti, Gilberte Robain \\ ER6 - Université Pierre et marie Curie (Paris 06) (FAV, GR); Service de Médecine Physique et Rééducation \\ (Neurologie) (FAV, GR), Hôpital Rothschild and Service de Rééducation, Hôpital Saint Antoine (BGM), \\ Paris, France
}

\section{ABSTRACT}

Objectives: To evaluate the urodynamic characteristics of the two patterns (phasic, $\mathrm{P}$ and terminal, T) of detrusor overactivity (DO) according to gender and neurological condition. Materials and Methods: Urodynamic characteristics of DO were analysed in a population with proven urodynamic DO (127 women and 76 men, respectively with 48 and 43 neurological diseases (encephalic, incomplete medullar lesion or peripheral)). Phasic D0 is characterized by phasic waves with or without leakage while terminal DO is defined by a single non-inhibited contraction resulting in incontinence. Parameters analysed for both patterns of DO (among other parameters) included: volume and amplitude of the first non-inhibited detrusor contraction (NIDC\#1), and for phasic D0: duration of pressure rise during NIDC\# 1 and number of NIDC.

Results: Phasic DO was observed in younger patients in the whole population whatever the gender (women: 55.9 years vs. 64.7 years, $\mathrm{p}=0.0052$; men: 57.4 years vs. 67.8 years, $\mathrm{p}$ $=0.0038$ ). Volume at NIDC\# 1 was greater for neurological PDO (significant in women: 185 vs. $125 \mathrm{~mL}, \mathrm{p}=0.0223$ ). Other parameters were not significantly different whatever the gender. Amplitude of NIDC\# 1 during PDO was significantly lower than that of NIDC during terminal DO (TDO) in both genders whatever the neurological condition ( $<<0.0001$ ). Volume at NIDC\#1 in both patterns was dependent on the level of neurological lesion. Conclusion: The main difference between the patterns of DO is that PDO occurs in younger individuals. There is no significant difference between urodynamic characteristics of each pattern whatever gender or neurological status. Further studies will provide additional information on the impact of the level of neurological lesion on the pattern of DO.

\section{ARTICLE INFO}

\section{Key words:}

Urinary Bladder, Overactive; Urodynamics; Female; Male

Int Braz J Urol. 2013; 39: 663-70

Submitted for publication: January 30, 2013

Accepted after revision:

August 15, 2013

\section{INTRODUCTION}

Detrusor overactivity (DO) is a frequent urodynamic diagnosis in patients with urge syndrome and is defined by non-inhibited detrusor contractions (NIDC) during the filling phase. According to the International Continence Society (ICS) standardisation (1), two patterns of DO are described. Phasic D0 (PD0) is characterized by phasic waves with or without leakage, while terminal DO (TDO) is defined by a single NIDC which cannot be suppressed and often results in incontinence (usually bladder emptying). In addition, DO is also qualified according to cause as idiopathic (IDO, no defined cause) or neurogenic (NDO, relevant neurological condition). 
Some attempts have been made, in women, to evaluate the differences in urodynamic characteristics between IDO and NDO secondary to multiple sclerosis (2) and diabetes (3). The pattern of DO has rarely been taken into account but it has been reported that TDO was more frequent in old women with or without history of neurological disease (4). In men, occurrence of TDO was reported in elderly (5), in patients with Parkinson's disease (6), and the different patterns of DO described in patients with benign prostatic hyperplasia $(7,8)$. DO is frequently observed in patients with history of neurological disease (9).

The aim of the present study was to determine in there are differences in urodynamic characteristics between idiopathic and neurogenic D0 patterns according to gender. In case of neurological condition, if there are differences according to the level of neurological impairment (central, spinal or peripheral).

\section{MATERIALS AND METHODS}

Urodynamic studies of patients referred to our laboratory for evaluation of lower urinary tract dysfunction over the period January 2007 to December 2009 were retrospectively analyzed. Only patients with DO during urodynamics were included. DO was defined as an involuntary rise of detrusor pressure $\left(\mathrm{p}_{\text {det }}\right)$ greater than $5 \mathrm{~cm} \mathrm{H} \mathrm{H}_{2} \mathrm{O}$ during filling. No provocative maneuvers were conducted to elicit DO.

Exclusion criteria included pelvic organ prolapse of grade 2 or greater, complete spinal cord injury, diabetes mellitus, and anticholinergic treatment.

A total of 203 patients (127 women and 76 men, respectively 48 and 43 with neurological disease (encephalic, incomplete medullar or peripheral lesion)) fulfilled the inclusion criteria.

All patients had evaluation including medical history and usual medication, bladder diary for at least 48 hours including voiding times and voided volumes during day- and night-time, physical examination and dipstick urinalysis.

Cystometry was performed with the patient in the seated position with a $7 \mathrm{~F}$ triple-lumen urethral catheter perfused with saline at room temperature, using a filling rate of $50 \mathrm{~mL} / \mathrm{min}$. Pressure transducers were zeroed to atmospheric pressure at the upper edge of the symphysis pubis. Rectal pressure was recorded using a punctured intrarectal balloon catheter filled with $2 \mathrm{~mL}$ of saline according to the report of Good Urodynamic Practice Guidelines (10).

Recordings were reviewed independently by two investigators. In case of discrepancy (about $10 \%$ of the files) an additional interpretation was made jointly to reach a single conclusion.

For both patterns of D0, the volume and the amplitude of the first NIDC were measured. For PDO, the duration of detrusor pressure rise during the first NIDC (NIDC\#1), the number of NIDC and the occurrence of NIDC at cystometric capacity were also measured. The characteristics of the first NIDC were analysed because, sometimes, only one NIDC was observed during PDO.

For both patterns, other recorded urodynamic parameters included cystometric capacity, maximum flow rate $\left(Q_{\max }\right)$, detrusor pressure at maximum flow (pdet. $Q_{\max }$ ), voided volume $\left(\mathrm{V}_{\mathrm{v}}\right)$ and post void residual volume (PVR).

When looking at the neurological status, female and male population were non homogeneous; thus each gender was separately analyzed.

This study was conducted in accordance to the Declaration of Helsinki. According to the local practice of our Ethics Committee, there is no formal Institutional Review Board approval required for retrospective studies.

\section{Statistical analysis}

Data are presented as mean \pm SD and range. $t$ test, analysis of variance (ANOVA) and the chi-square test were used as appropriate. All statistical results were considered significant at $p<0.05$. Statistical analyses were performed using SAS, version 5.0 (SAS Institute, Inc., Cary, NC).

\section{RESULTS}

\section{Detrusor overactivity pattern vs. neurological status}

The localisation of the neurological lesion is resumed in Table-1. In ND0 patients, NIDC\#1 during PDO occurred at lower bladder volume than 
NIDC of TDO in patients with encephalic lesion while NIDC during TDO occurred at lower bladder volume than NIDC\# 1 of PDO in patients with medullar lesion (Table-2).

There was no significant difference in the occurrence of a pattern of DO with the neurologic status whatever the gender.

Female population

Results are summarized in Table-3. There was no significant difference in the clinical baseline of the female population; the chief complaint was urgency (urge or mixed incontinence). Other voiding complaints were dysuria, frequency and incomplete emptying.
PDO patients were significantly younger in the whole population: $55.9 \pm 19.5$ vs. $64.7 \pm 15.1$ years ( $p=0.0052)$ and in the NDO subgroup: 49.7 \pm 19.7 vs. $59.2 \pm 18.2$ years $(p=0.0407)$. NDO subgroups were significantly younger according to each pattern of D0: $49.7 \pm 19.7$ vs. $59.8 \pm 18.5$ years $(\mathrm{p}=0.0468)$ for PD0 sub-group and $59.2 \pm 18.2 \mathrm{vs}$. $68.0 \pm 11.9$ years $(\mathrm{p}=0.0223)$ for TD0 sub-group.

\section{women)}

Phasic detrusor overactivity (PD0, 65 The volume of occurrence of the first contraction (NIDC\#1) was higher in the NDO group $(185 \pm 116 \mathrm{~mL}$ vs. $125 \pm 89 \mathrm{~mL}, \mathrm{p}=0.0223)$ while the increasing time of $\mathrm{p}_{\text {det }}(7.5 \pm 2.7 \mathrm{~s}$ vs. $7.8 \pm$

Table 1 - Localisation of the neurological lesion in each gender vs. pattern of detrusor overactivity (PDO: phasic detrusor overactivity, TD0: terminal detrusor overactivity).

\begin{tabular}{lcccc}
\hline Localisation & & Encephalic & Medullar & Peripheral \\
\hline Women (No 48) & PD0 (No 25) & $7(28 \%)$ & $16(64 \%)$ & $2(8 \%)$ \\
& TD0 (No 23) & $14(61 \%)$ & $9(39 \%)$ & 0 \\
Men (No 43) & PD0 (No 16) & $10(62.5 \%)$ & $4(25 \%)$ & $2(12.5 \%)$ \\
& TD0 (No 27) & $15(55.5 \%)$ & $11(40.7 \%)$ & $1(3.7 \%)$ \\
\hline
\end{tabular}

Table 2 - Volume at the first non-inhibited detrusor contraction (NIDC\#1) for patients with neurological detrusor overactivity (NDO) vs. level of neurological lesion (PDO: phasic detrusor overactivity, TDO: terminal detrusor overactivity).

\begin{tabular}{lccccc}
\hline Lesion Level & Gender & No PDO & V NIDC\#1 mL & No TDO & V NIDC mL \\
\hline Encephalic & Women & 7 & $117 \pm 97$ & 14 & $176 \pm 102$ \\
& Men & 10 & $164 \pm 129$ & 15 & $328 \pm 167$ \\
Medullar & Women & 16 & $212 \pm 113$ & 9 & $116 \pm 56$ \\
& Men & 4 & $264 \pm 182$ & 11 & $217 \pm 138$ \\
Peripheral & Women & 2 & $161 \pm 108$ & 0 & -- \\
& Men & 2 & $282 \pm 33$ & 1 & 186 \\
\hline
\end{tabular}


Table 3 - Demographic and urodynamic characteristics of the female population (PDO: phasic detrusor overactivity, TDO: terminal detrusor overactivity, NDO: neurogenic detrusor overactivity, IDO: idiopathic detrusor overactivity, NIDC non-inhibited detrusor contraction, PVR post void residual volume, Qmax maximum flow rate, pdet.Qmax detrusor pressure at maximum flow rate).

\begin{tabular}{|c|c|c|c|c|c|c|}
\hline \multirow[t]{2}{*}{ Parameter } & \multicolumn{3}{|c|}{ PDO (No 65) } & \multicolumn{3}{|c|}{ T DO (№ 62) } \\
\hline & $\begin{array}{c}\text { NDO } \\
\text { (No 25) }\end{array}$ & $\begin{array}{c}\text { IDO } \\
\text { (№ 40) }\end{array}$ & $p$ & $\begin{array}{c}\text { NDO } \\
\text { (No 23) }\end{array}$ & $\begin{array}{c}\text { IDO } \\
\text { (№ 39) }\end{array}$ & $p$ \\
\hline Age (y) & $49.7 \pm 19.7$ & $59.8 \pm 18.5$ & 0.0407 & $59.2 \pm 18.2$ & $68.0 \pm 11.9$ & 0.0144 \\
\hline \multicolumn{7}{|l|}{ Major complaint } \\
\hline Urge inc. & $56.0 \%$ & $50.0 \%$ & & $52.2 \%$ & $56.4 \%$ & \\
\hline Mixed inc. & $8.0 \%$ & $25.0 \%$ & & $21.7 \%$ & $20.5 \%$ & \\
\hline Stress inc. & -- & -- & & -- & $10.2 \%$ & \\
\hline Other & $36.0 \%$ & $25.0 \%$ & & $26.1 \%$ & $12.8 \%$ & \\
\hline \multicolumn{7}{|l|}{ NIDC } \\
\hline $\mathrm{V}(\mathrm{NIDC} \# 1)(\mathrm{mL})$ & $185 \pm 116$ & $125 \pm 89$ & 0.0223 & $154 \pm 90$ & $274 \pm 126$ & $<0.0001$ \\
\hline Amplitude NIDC \#1 $\left(\mathrm{cm} \mathrm{H}_{2} 0\right)$ & $15.5 \pm 11.9$ & $11.5 \pm 9.6$ & n.s. & $48.7 \pm 36.2$ & $41.5 \pm 22.0$ & n.s. \\
\hline Rising time NIDC \#1 (s) & $7.5 \pm 2.7$ & $7.8 \pm 3.4$ & n.s. & & & \\
\hline No NIDC & $3.1 \pm 1.5$ & $3.3 \pm 1.9$ & & & & \\
\hline Amplitude last NIDC $\left(\mathrm{cm} \mathrm{H}_{2} \mathrm{O}\right)$ & $25.1 \pm 22.1$ & $27.8 \pm 21.5$ & n.s. & & & \\
\hline Cystometric Capacity mL & $323 \pm 125$ & $284 \pm 127$ & n.s. & $175 \pm 92$ & $302 \pm 127$ & $<0.0001$ \\
\hline PVR (mL) & $182 \pm 145$ & $67 \pm 92$ & 0.0017 & $77 \pm 87$ & $112 \pm 111$ & n.s. \\
\hline$Q_{\max }(\mathrm{mL} / \mathrm{s})$ & $7 \pm 4$ & $12 \pm 6$ & 0.0101 & $8 \pm 6$ & $9 \pm 5$ & n.s. \\
\hline$p_{\text {det }} \cdot Q_{\max }\left(\mathrm{cm} \mathrm{H}_{2} 0\right)$ & $40.9 \pm 16.5$ & $36.6 \pm 17.0$ & n.s. & $36.1 \pm 23.1$ & $32.4 \pm 13.9$ & n.s. \\
\hline
\end{tabular}

3.4s) and the amplitude of NIDC\# $1(15.5 \pm 11.9 \mathrm{~cm}$ $\mathrm{H}_{2} \mathrm{O}$ vs. $11.5 \pm 9.6 \mathrm{~cm} \mathrm{H}_{2} \mathrm{O}$ ) did not differ between NDO and IDO sub-groups.

Between NDO and ID0 sub-groups, there was no difference in the number of NIDC (3.1 \pm 1.5 vs. $3.3 \pm 1.9)$ nor in the amplitude of the last NIDC $\left(25.1 \pm 22.1 \mathrm{~cm} \mathrm{H}_{2} \mathrm{O}\right.$ vs. $\left.29.4 \pm 21.3 \mathrm{~cm} \mathrm{H}_{2} \mathrm{O}\right)$.
There was a significant increase of amplitude between amplitude of the first and the last NIDC whatever the neurologic status (NDO: $15.5 \pm$ $11.9 \mathrm{~cm} \mathrm{H} 2 \mathrm{O}$ vs. $25.1 \pm 22.1 \mathrm{~cm} \mathrm{H}_{2} \mathrm{O} \mathrm{p}=0.0095$; IDO: $13.1 \pm 10.7 \mathrm{~cm} \mathrm{H}_{2} \mathrm{O}$ vs. $\left.27.8 \pm 21.5 \mathrm{~cm} \mathrm{H}_{2} \mathrm{O} \mathrm{p}<0.0001\right)$.

Looking at the occurrence of a NIDC at cystometric capacity, there was only a sig- 
Table 4 - Demographic and urodynamic characteristics of the male population (PDO: phasic detrusor overactivity, TDO: terminal detrusor overactivity, NDO: neurogenic detrusor overactivity, IDO: idiopathic detrusor overactivity, NIDC non-inhibited detrusor contraction, PVR post void residual volume, Qmax maximum flow rate, pdet.Qmax detrusor pressure at maximum flow rate).

\begin{tabular}{|c|c|c|c|c|c|c|}
\hline \multirow[t]{2}{*}{ Parameter } & \multicolumn{3}{|c|}{ PD0 (№ 31 ) } & \multicolumn{3}{|c|}{ TDO (№ 45) } \\
\hline & $\begin{array}{c}\text { NDO } \\
\text { (No 16) }\end{array}$ & $\begin{array}{c}\text { IDO } \\
\text { (№ 15) }\end{array}$ & $p$ & $\begin{array}{c}\text { NDO } \\
\text { (№ 27) }\end{array}$ & $\begin{array}{c}\text { IDO } \\
\text { (№ 18) }\end{array}$ & $\mathrm{p}$ \\
\hline Age (y) & $53.0 \pm 22.1$ & $62.1 \pm 11.8$ & n.s. & $66.4 \pm 12.5$ & $70.0 \pm 12.0$ & n.s. \\
\hline \multicolumn{7}{|l|}{ Major complaint } \\
\hline Urge inc. & $25.0 \%$ & $50.0 \%$ & & $48.1 \%$ & $33.3 \%$ & \\
\hline Mixed inc. & $6.2 \%$ & $33.3 \%$ & & $22.2 \%$ & $11.1 \%$ & \\
\hline Stress inc. & -- & -- & & -- & -- & \\
\hline Other & $68.7 \%$ & $16.7 \%$ & & $29.6 \%$ & $55.5 \%$ & \\
\hline \multicolumn{7}{|l|}{ NIDC } \\
\hline $\mathrm{V}(\mathrm{NIDC} \# 1)(\mathrm{mL})$ & $201 \pm 153$ & $168 \pm 107$ & n.s. & $278 \pm 162$ & $211 \pm 84$ & n.s. \\
\hline amplitude NIDC \#1 ( $\left.\mathrm{cm} \mathrm{H}_{2} \mathrm{O}\right)$ & $22.1 \pm 18.8$ & $14.7 \pm 13.0$ & n.s. & $57.3 \pm 30.5$ & $65.8 \pm 39.8$ & n.s. \\
\hline rising time NIDC \#1 (s) & $10.1 \pm 6.4$ & $7.3 \pm 2.7$ & n.s. & & & \\
\hline No NIDC & $4.2 \pm 4.0$ & $3.3 \pm 1.8$ & n.s. & & & \\
\hline amplitude last NIDC $\left(\mathrm{cm} \mathrm{H}_{2} \mathrm{O}\right)$ & $43.1 \pm 27.0$ & $46.0 \pm 40.9$ & n.s. & & & \\
\hline Cystometric capacity mL & $344 \pm 167$ & $295 \pm 118$ & n.s. & $300 \pm 163$ & $249 \pm 96$ & n.s. \\
\hline PVR (mL) & $104 \pm 113$ & $102 \pm 108$ & n.s. & $129 \pm 137$ & $58 \pm 65$ & n.s. \\
\hline$Q_{\text {max }}(\mathrm{mL} / \mathrm{s})$ & $8 \pm 6$ & $10 \pm 9$ & n.s. & $6 \pm 3$ & $6 \pm 3$ & n.s. \\
\hline $\mathrm{p}_{\text {det. }} \mathrm{Q}_{\max }\left(\mathrm{cm} \mathrm{H}_{2} \mathrm{O}\right)$ & $56.0 \pm 40.6$ & $51.2 \pm 28.7$ & n.s. & $57.9 \pm 28.2$ & $66.3 \pm 36.4$ & n.s. \\
\hline
\end{tabular}

n.s = not significant

nificant difference with age; this phenomenon was more frequent in older patients $(60.3 \pm 18.3$ years vs. $47.4 \pm 19.3$ years, $p=0.0103$ ). women)

Terminal detrusor overactivity (TD0, 62

The volume at onset of NIDC was significantly greater in IDO patients $(274 \pm 126 \mathrm{~mL}$ vs. $154 \pm 90 \mathrm{~mL}, \mathrm{p}<0.0001)$.
During TD0, amplitude of NIDC was significantly greater than that of NIDC\# $1 \mathrm{du}-$ ring PDO whatever the neurological condition: for $\mathrm{NDO} 48.7 \pm 36.2 \mathrm{~cm} \mathrm{H}_{2} \mathrm{O}$ vs. $15.5 \pm 11.9 \mathrm{~cm} \mathrm{H}_{2} \mathrm{O}$ (p $<0.0001)$ and for IDO $41.5 \pm 22.0 \mathrm{~cm} \mathrm{H}_{2} \mathrm{O}$ vs. $11.5 \pm$ $9.6 \mathrm{~cm} \mathrm{H}_{2} \mathrm{O}(\mathrm{p}<0.0001)$.

Male population

Results are summarized in Table-4. 
There was no significant difference in the clinical baseline of the male population; the chief complaint was urgency (urge or mixed incontinence). The chief complaint was urgency (urge and mixed incontinence). Patients with history of neurologic disease had less incontinence complaint in the PDO group.

Pressure flow study was obtained in $63(83 \%)$ men. Looking at a possible bladder outlet obstruction (according to A-G number criterion), 30 men were found obstructed from which 9 had PDO and 21 TD0. In the non-obstructed (18 men) and equivocal (15 men) groups the difference in terms of D0 was respectively 9 PDO/9 TDO and 6 PDO/9 TDO.

PDO patients were significantly younger in the whole population $57.4 \pm 18.2$ years vs. $67.8 \pm 12.3$ years $(\mathrm{p}=0.0038)$ and in the NDO sub-group $53.0 \pm 22.1$ years vs. $66.4 \pm 12.5$ years $(p$ $=0.0149$ ). In each pattern, ND0 patients were younger but not significantly.

Phasic detrusor overactivity (PDO, 31 men) In PDO patients, there was no significant difference in the volume at NIDC\#1 $1201 \pm$ $153 \mathrm{~mL}$ vs. $168 \pm 107 \mathrm{~mL}$ ), the increasing time of $\mathrm{p}_{\text {det }}$ $(10.1 \pm 6.4 \mathrm{~s}$ vs.7.3 $\pm 2.7 \mathrm{~s})$, the amplitude of NIDC \# 1 $\left(22.1 \pm 18.8 \mathrm{~cm} \mathrm{H}_{2} \mathrm{O}\right.$ vs. $\left.14.7 \pm 13.0 \mathrm{~cm} \mathrm{H}_{2} \mathrm{O}\right)$, the number of NIDC $(4.2 \pm 4.0$ vs. $3.3 \pm 1.8)$ and the amplitude of the last NIDC between NDO and IDO sub-groups.

There was a significant difference between amplitude of the first and the last NIDC whatever the neurologic status (NDO: $22.1 \pm 18.8$ $\mathrm{cm} \mathrm{H}_{2} \mathrm{O}$ vs. $43.1 \pm 27.0 \mathrm{~cm} \mathrm{H}_{2} \mathrm{O} \mathrm{p}=0.0250$; IDO: 14.7 $\pm 13.0 \mathrm{~cm} \mathrm{H} \mathrm{H}_{2} \mathrm{O}$ vs. $46.0 \pm 40.9 \mathrm{~cm} \mathrm{H}_{2} \mathrm{O} \mathrm{p}=0.0211$ ).

Looking at the occurrence of a NIDC at cystometric capacity, there was no significant difference according to neurologic condition or with age.

\section{Terminal detrusor overactivity (45 men)}

The volume at onset of NIDC was not significantly different between IDO and NDO patients $(211 \pm 84 \mathrm{~mL}$ vs. $278 \pm 162 \mathrm{~mL})$.

The amplitude of NIDC during TDO was significantly greater than that of NIDC\#1 during PDO whatever the neurological condition: for
NDO $57.3 \pm 30.5 \mathrm{~cm} \mathrm{H} 2 \mathrm{O}$ vs. $22.1 \pm 18.8 \mathrm{~cm} \mathrm{H} 2 \mathrm{O}$ (p $=0.0002)$ and for IDO $65.8 \pm 39.8 \mathrm{~cm} \mathrm{H} 20$ vs. 14.7 $\pm 13.0 \mathrm{~cm} \mathrm{H}_{2} \mathrm{O}(\mathrm{p}<0.0001)$.

During PDO, amplitude of NIDC\# 1 was significantly lower than amplitude of NIDC during TD0 whatever the neurological condition: for NDO $22.1 \pm 18.8 \mathrm{~cm} \mathrm{H} 2 \mathrm{O}$ vs. $57.3 \pm 30.5 \mathrm{~cm} \mathrm{H} 2 \mathrm{O}$ (p $=0.0002)$ and for IDO $14.7 \pm 13.0 \mathrm{~cm} \mathrm{H} 20$ vs. 65.8 $\pm 39.8 \mathrm{~cm} \mathrm{H}_{2} \mathrm{O}(\mathrm{p}<0.0001)$.

\section{DISCUSSION}

Two great theories, neurogenic and myogenic, are proposed to explain detrusor overactivity. It is accepted that multiple events in the urothelium, sub-urothelium and possibly in the detrusor muscle are implied (11). If these theories tried to explain the triggering mechanism, no distinction was made between the patterns of DO defined by the ICS (1). Hypothesis is that the mechanism underlying PDO and TDO could be not the same and could involve differences in urodynamic parameters of detrusor function. Some studies tried to determine whether urodynamic parameters differ between patients, with or without neurological condition, who have detrusor overactivity $(2,3,6)$. These studies analyzed mainly data from women $(2,3)$ and did not make any difference between the two patterns (phasic and terminal) of DO.

In the present study, we add two new contributions since we compare urodynamic data of D0 patients of both genders according to the two patterns of DO.

An important result is that there are some similarities between the expression of PDO in both genders whatever the neurological condition. There is no significant difference between the characteristics of the NIDC\# 1 (amplitude, rising time), between the number of NIDC and between the amplitude of the last NIDC. In both genders, the amplitude of the last NIDC is significantly greater than that of NIDC\# 1 which is consistent with the absence of detrusor fatigability during filling. Our finding about the amplitude of NIDC\#1 (no difference between NDO and ID0) is opposite to the findings of Lemack (2) and Golabeck (3) and can be explained since they don't make distinction between PDO and TDO. 
It has been reported that "phasic detrusor overactivity tends to be characterized by contractions of increasing amplitude as the bladder volume increases" (12). That behaviour is more frequently observed when the number of NIDC is small. Increased amplitude of NIDC with bladder filling can be related to an increasing difficulty to abort detrusor contraction with increased bladder volume. Using a mathematical model of micturition, it has been proposed (13) that in ID0, the nervous control of PDO implies in an inhibitory reflex which stops the contraction after a $5 \mathrm{~s}$ delay while that reflex is inadequate in TDO. It has been also proposed (13) that during TDO, the inadequate inhibitory reflex allows the increase of detrusor pressure. A remaining question, needing further studies, is: is that reflex more intricate and dependent on the bladder volume?

Influence of age is observed in both genders, and PDO occurs in younger individuals. That result is consistent with previous results (4) but in our study, women with ND0 ( $\mathrm{P}$ or $\mathrm{T}$ ) are younger than women with IDO. Men with NDO are also younger but not significantly. Occurrence of an NIDC at cystometric capacity does not depend on the neurological status but is more frequent in older.

In a male population with symptomatic benign prostatic enlargement of which $86 \%$ were categorized as obstructed (following BOOI i.e. A-G number), TD0 was found predominantly in 55\% (8). That result correlates bladder outlet obstruction and TDO which is similar to our finding.

Interestingly, comparing patients with encephalic or medullar lesion, we find that in the NPDO population, NIDC\#1 occurs at a smaller volume than NIDC of TDO in patients with encephalic lesion whatever the gender. When looking at the volume at onset of NIDC\# 1, patients with encephalic lesion have the same behaviour than patients with IDO. That result is consistent with the commonest cystometric finding in stroke: DO with normally coordination voiding (11).

On the opposite, the NIDC of TDO occurs at a lower bladder volume than NIDC\# 1 during PDO in case of medullar lesion. These findings must be compared with those of Lemack et al. (2) and those of Golabek et al. (3) as they both observe DO later in their NDO group with respectively multiple sclerosis and diabetes mellitus but they don't distinguish be- tween phasic and terminal DO. Lower urinary tract dysfunction secondary to multiple sclerosis is mainly the result of spinal cord disease (14) while both central and peripheral mechanisms are implicated in diabetic patients (15). An unexpected result is that PDO is not prevalent in the medullar population (incomplete lesion) while it is known that a dyssynergic behaviour is observed in patients with complete lesion (16). In complete spinal cord injury, the most common idea is that PDO is predominant. In fact, clinicians have observed that occurrence of PDO decreased with clean intermittent catheterization.

Although the NDO sub-groups are not of sufficient size to conclude, our results provide a first insight of a possible different expression of DO according to the level of neurological lesion. Further studies are needed to obtain additional information about the pattern of DO.

The limitation of our study is that it is retrospective which induces a bias due to the recruitment of our urodynamic laboratory, but it is to our knowledge the first study that tries to find differences in the urodynamic expression of the two patterns of DO.

\section{CONCLUSIONS}

The main difference between the patterns of DO is that PDO occurs in younger individuals. There is no significant difference between urodynamic characteristics of each pattern whatever gender, complaint and neurological status. If there is a tendency for a first NIDC of higher amplitude in NDO patients (except NTDO men), that finding does not allow conclude for an increased outlet resistance. Further studies will provide additional information on the impact of the level of neurologic lesion on the pattern of DO.

\section{ABBREVIATIONS}
DO = Detrusor overactivity
IDO = Idiopathic detrusor overactivity
ICS = International Continence Society
NDO = Neurologic detrusor overactivity
NIDC, NIDC\# 1 = Non-inhibited detrusor contrac- tion, first NIDC 
NPDO, NTDO = Neurologic phasic detrusor overactivity, neurologic terminal detrusor overactivity $\mathrm{P}_{\mathrm{det}}=$ Detrusor pressure PDO = Phasic detrusor overactivity PVR $=$ Post void residual volume $\mathrm{Q}_{\max }=$ Maximum flow rate TDO $=$ Terminal detrusor overactivity

\section{CONFLICT OF INTEREST}

\section{None declared.}

\section{REFERENCES}

1. Abrams P, Cardozo L, Fall M, Griffiths D, Rosier P, Ulmsten U, et al.: The standardisation of terminology of lower urinary tract function: report from the Standardisation Sub-committee of thelnternational Continence Society. Neurourol Urodyn. 2002; 21: 167-78.

2. Lemack GE, Frohman EM, Zimmern PE, Hawker K, Ramnarayan $\mathrm{P}$ : Urodynamic distinctions between idiopathic detrusor overactivity and detrusor overactivity secondary to multiple sclerosis. Urology. 2006; 67: 960-4.

3. Golabek T, Kiely E, O'Reilly B: Detrusor overactivity in diabetic and non-diabetic patients: is there a difference? Int Braz $\mathrm{J}$ Urol. 2012; 38: 652-9; discussion 660.

4. Valentini FA, Marti BG, Robain G, Nelson PP: Phasic or terminal detrusor overactivity in women: age, urodynamic findings and sphincter behavior relationships. Int Braz J Urol. 2011; 37: $773-80$.

5. Kessler TM, Madersbacher $\mathrm{H}$. Urodynamic phenomena in the aging bladder. Urologe A. 2004; 43: 542-6.

6. Defreitas GA, Lemack GE, Zimmern PE, Dewey RB, Roehrborn CG, O'Suilleabhain PE: Distinguishing neurogenic from nonneurogenic detrusor overactivity: a urodynamic assessment of lower urinary tract symptoms in patients with and without Parkinson's disease. Urology. 2003; 62: 651-5.

7. Tong YC: Comparisons of urodynamic findings and voiding habits in patients with concomitant benign prostatic hyperplasia and detrusor overactivity presenting with or without the symptom of urgency. Urol Int. 2007; 78: 219-25.
8. Shahab N, Seki N, Takahashi R, Kajioka S, Takei M, Yamaguchi A, Naito S: The profiles and patterns of detrusor overactivity and their association with overactive bladder symptoms in men with benign prostatic enlargement associated with detrusor overactivity. Neurourol Urodyn. 2009; 28: 953-8.

9. Leu PB, Diokno AC. Epidemiology of the neurogenic bladde. In Neurogenic bladder. J Corcos and E Schick ed. Martin Dunitz Ltd. Boca Raton FL USA. 2004; pp. 91-104.

10. Schäfer W, Abrams P, Liao L, Mattiasson A, Pesce F, Spangberg $A$, et al:: Good urodynamic practices: uroflowmetry, filling cystometry, and pressure-flow studies. Neurourol Urodyn. 2002; 21: 261-74.

11. Ashok K, Wang A: Detrusor overactivity: an overview. Arch Gynecol Obstet. 2010; 282: 33-41.

12. Abrams P: Describing bladder storage function: overactive bladder syndrome and detrusor overactivity. Urology. 2003; 62(5 Suppl 2): 28-37.

13. Nelson PP, Valentini FA. Nervous control of lower urinary tract (LUT) function during detrusor overactivity (D0). An approach using modeled analysis of filling cystometries and pressureflow studies. S.U.F.U. Annual Winter Meeting Phoenix AZ (USA). 2011; March 1-5th.

14. Fowler CJ, Panicker JN, Drake M, Harris C, Harrison SC, Kirby $\mathrm{M}$, et al:: A UK consensus on the management of the bladder in multiple sclerosis. J Neurol Neurosurg Psychiatry. 2009; 80: 470-7.

15. Yamaguchi $\mathrm{C}$, Sakakibara R, Uchiyama $\mathrm{T}$, Yamamoto $\mathrm{T}$, Ito $\mathrm{T}$, Liu Z, et al.: Overactive bladder in diabetes: a peripheral or central mechanism? Neurourol Urodyn. 2007; 26: 807-13.

16. Siroky MB, Krane RJ: Neurologic aspects of detrusor-sphincter dyssynergia, with reference to the guarding reflex. J Urol. 1982; 127: 953-7.

Correspondence address:

Dr. Françoise A. Valentini Service de Médecine Physique et Rééducation (Neurologie), Hôpital Rothschild, 5, rue Santerre, 75012 - Paris, France. Fax: + 331 4019- 3656 E-mail: favalentini@gmail.com 